\title{
A Família como Centralidade nas Políticas Públicas e as Novas Composições Familiares: A adequação jurídica, política e temporal sobre a família contemporânea
}

\author{
Zolnei Vargas Ernesta de Córdova ${ }^{1}$; Ismael de Córdova ${ }^{2}$; Katiuscia Angélica Micaela de Oliveira ${ }^{3}$
}

\begin{abstract}
Resumo: O presente artigo se dará, em suas apreciações históricas e legais, discutir o tema das políticas públicas nas novas composições familiares. Dialogando com autores e comentadores do assunto, poderse-á traçar um apanhado do que envolvia sobre o conceito de família no período colonial, bem como nas composições indígenas e escravas que colaboraram de modo expressivo para a constituição familiar do Brasil. Não obstante, este artigo se debruçará, também, sobre a evolução da instituição familiar no Brasil; assinalando as composições familiares e como se definiam em tal concepção com base na legislação brasileira, como na declaração dos direitos humanos. Por fim, sem esgotar as possibilidades de debate sobre o assunto, se versará sobre a família e as novas composições familiares de acordo com as políticas públicas de assistência social, como das atribuições do estado em relação a essas famílias assistidas legalmente.
\end{abstract}

Palavras-Chave: Políticas Públicas, Direitos adquiridos; Novas composições familiares.

\section{The Family as a Centrality in Public Policies and new Family Compositions: the legal, political and temporal adequacy of the contemporary family}

\begin{abstract}
This article in its historical and legal assessments, aim to discuss the theme of public policies in the new family compositions. Dialogging with authors and commentators on the subject, it will be possible to trace an overview of what involved the concept of family in the colonial period, as well as the indigenous and slave compositions that collaborated in an expressive way for the Brazilian family constitution. Nevertheless, this article will also look at the evolution of the family institution in Brazil; marking the family compositions and how they were defined in this conception based on Brazilian legislation, as in the declaration of human rights. Finally, without exhausting the possibilities of debate on the subject, the family and the new family compositions will be addressed in accordance with public social assistance policies, as well as the state's responsibilities in relation to these legally assisted families.
\end{abstract}

Keywords: Public Policies, Acquired Rights; New family compositions.

\footnotetext{
${ }^{1}$ Docente do Curso de Psicologia da UNESC. Psicólogo Clínico. Especialista em Sistema Único de Assistência Social - SUAS. Especialização em andamento em Abordagem Sistêmica Familiar. zolnei@unesc.net

${ }^{2}$ Mestrado em Desenvolvimento Socioeconômico pela Universidade do Extremo Sul Catarinense, Brasil. Docente do curso de direito da UNESC. Advogado OAB/SC 37.447. Doutorando em Desenvolvimento socioeconômico pela Universidade do Extremo Sul Catarinense, UNESC, Brasil. Especialista em Sistema Único de Assistência Social - SUAS. Especialista em Direito Público com Ênfase Gestão Pública. Idc@unesc.net

${ }^{3}$ Mestra em Ciências da Linguagem pela Universidade do Sul de Santa Catarina na linha de pesquisa Linguagem e Cultura. Especialista em História da Arte Faculdade de Capivari. Graduação em Artes Visuais pela Universidade do Extremo Sul Catarinense. Docente do quadro especial da Universidade do Extremo Sul Catarinense/Unesc. katiusciakamo@gmail.com.
} 


\section{Introdução}

Partindo de uma contextualização temporal sobre o conceito de família em sua apreensão histórica, este trabalho se desenvolverá num primeiro momento, por meio da evolução da instituição familiar no Brasil. Ou seja, os tipos de composições familiares em sua definição e de como se envolvia a apreciação conceitual de família entre colonizadores, indígenas e escravos que, ressalvado suas singularidades, cederam ampla contribuição cultural no que tange as considerações de família na história do Brasil.

Não obstante, mesmo principiando-se de tais premissas históricas, este trabalho almeja em seu alargamento, compreender a constituição institucional de algo mais complexo que a mera definição de família nuclear, ao adentrar num campo de desenvolvimento e transformação que se dá constantemente e visivelmente diferenciado na contemporaneidade sobre o que é família e quais as novas composições que a definem na atualidade ao incluir essa instituição como um processo social em construção, desmitificando e até desnaturalizando aquela definição, que pela história, fora colocado e fundado em um sistema de casamento, poderio e manutenção patriarcal. Ou seja, o modelo de família considerado arquétipo único a ser seguido na sociedade, em determinações pré-definidas de cada membro familiar: o patriarca, o papel da mulher, dos filhos e a interlocução das famílias com o poder estatal.

No entanto, numa consequência temporal e cultural, o conceito de família foi se transformando com a sociedade que a própria família é parte constituinte em sua atribuição institucional, social e política. De tal modo, num segundo momento, a pesquisa se desenvolverá a respeito da família e o novo arranjo familiar de acordo com legislação brasileira, relacionando essa evolução ao longo dos tempos com o que se apreende sobre o tema dentro da legislação, ora pela constituição de 1988, ora por documentos de acordos internacionais como da Declaração Universal dos Direitos Humanos (DUDH) e na Declaração Universal dos Diretos da Criança (DUDC). Assim, em detrimento ao que se entendia como família em períodos anteriores, de elementos definidos socialmente, numa construção patriarcal e nuclear, RODRIGUES (2004, esclarece que,

[...] o fim dessa discriminação contra a família assim formada ocorreu, em princípio, com a Constituição Federal de 1988, cujo art. 226, § $3^{\circ}$, proclama que a união estável entre o homem e a mulher representa uma entidade familiar, que está sob a proteção do Estado, independentemente de matrimônio. Adiante, no $\S 4^{\circ}$, do mesmo dispositivo constitucional, atribuísse igualmente a qualidade de entidade familiar à comunidade constituída por um dos pais e seus descendentes (Rodrigues,2004, p. 13-14). 
Em consequência dessa evolução e desta nova gramática familiar, que mesmo sob os meandros complexos entre família, estado e igreja, que por vezes se confundem no sensocomum, e em outras se distinguem bruscamente em suas acepções, esse trabalho se justifica nos termos da constituição e de acordos universais supracitados, nas bases bibliográficas que lhe explicitam e dialogam o tema, ao passo que, por exemplo, no âmbito nacional, a Constituição Federal de 88 percebe a família sendo a base da sociedade e, portanto, alvo da proteção e promoção das políticas públicas de Assistência Social, o que permite considerar de extrema relevância investigar, de acordo com a literatura, como a Assistência Social tem se adequado para atender do modo que lhe é pertinente as famílias que se configuram dentro das mais diversas composições familiares pesquisados, uma vez que mesmo a constituição de 1988 tem se adequado ao abrangente conceito de família composta.

Por Fim, sem esgotar as possibilidades de debates profundos sobre o assunto, no terceiro momento deste artigo, a pesquisa se apresentará dentro da concepção da família e as novas composições familiares dentro da Assistência Social que, sob a base de uma política pública ética e sem preconceitos, devem ser garantidos, defendidos e assistidos legalmente.

\section{A Evolução da Instituição Familiar no Brasil: Tipos de Composições Familiares}

Para uma compreensão mais efetiva, esse artigo tratará num primeiro momento sobre a formação e a trajetória da família na história, analisando as diferentes relações sociais que se originaram no Brasil, considerando toda a influência cultural estabelecida pelos colonizadores, índios e escravos que formaram diferentes composições familiares ao longo do período colonial. Cada um com suas peculiaridades contribuem de forma significativa para a concepção de família em nosso país, como na compreensão do casamento e o papel de cada membro familiar: o patriarca, o papel da mulher, dos filhos e a relação da família como mantenedores do poder econômico, bem como das relações desta instituição com o Estado e a igreja. Ao longo da leitura, perceberemos as transformações sofridas na família, onde o senhor das terras era o protagonista e todos em sua volta lhe deviam obediência.

Mesmo ante a consciência de não ser um trabalho fácil esta análise histórica sobre o conceito de família, far-se-á uma abordagem temporal nos meandros complexos do tema, seja pela influência dos colonizadores, seja pela composição entre estado e igreja nas suas relações.

Assim, recorrendo à etimologia da palavra para este escopo, a palavra família provém de famulus que, segundo Zonabend (1996), estava ligada ao ato de servir ou ser servidor de 
alguém, no entanto, ainda conforme a autora, as relações familiares não possuíam uma correlação direta com a estrutura familiar atual ligada aos laços consanguíneos e/ou afetivos. Sua estrutura era muito mais ampla abarcando a todos que viviam sobre um mesmo teto e sob as ordens de um mesmo senhor, o pater famílias, que por sua vez, possuía total autoridade e controle sobre sua esposa, filhos, escravo e servidores, o que, portanto, nos leva ao entendimento de que inexistia uma família exclusivamente baseada em vínculos de parentesco ou de consanguinidade.

Concomitante à esta interpretação, a composição da família colonial no Brasil, ligada à esta apreensão ocidentalizada do termo, fez com que se fundamentasse uma família nuclear, patriarcal e de lugares previamente estabelecidos, onde relações das esferas privadas e públicas se misturam, e cedem ao homem o poder de decidir de modo extremamente horizontal, sem probabilidades de ascensão, assegurado pelo regime de servidão e autoridade. Logo,

\footnotetext{
[...] um extenso grupo composto pelo núcleo conjugal e sua prole legítima, ao qual se incorporavam parentes, afilhados, agregados, escravos e até mesmo concubinas e bastardos; todos abrigados sob o mesmo domínio, na casa-grande ou na senzala, sob a autoridade do patriarca, dono das riquezas, da terra, dos escravos e do mando político. Ainda caracterizada por traços tais como: baixa mobilidade social e geográfica, alta taxa de fertilidade e manutenção dos laços de parentesco com colaterais e ascendentes, tratando-se de um grupo multifuncional (TERUYA, 2000, p. $3-4)$.
}

Nessa conjuntura de preservação de relações econômicas entre os grupos familiares, impõem-se como regra, os casamentos arranjados pelos pais para seus filhos e filhas, que por sua vez, não consideravam a afetividade ou sentimentos, como o amor, entre os parceiros para selar o dito sacramento, o que interessava aos patriarcas, era principalmente a manutenção e ampliação do patrimônio familiar. Em outros casos, essa união poderia dar-se por interesses políticos, no qual um grupo familiar, requerendo adentrar nos meandros do poder com a finalidade de obter privilégios financeiros, buscava na parceria com outra família a possibilidade concreta de ascensão social e usufruto de cargos públicos que se reverteriam em benefícios econômicos. Como esclarece PIMENTEL (2005),

O casamento teria como razão a reprodução que justificaria as relações sexuais. Só assim adquiriria o selo da sacralidade e a benção divina, dentro de uma determinada relação normalizada. Este seria o primeiro sentido imposto ao casamento: estabelecer uma relação com Deus, ou seja, com o sagrado, desculpabilizando uma prática que de outra forma seria investida pelo pecado. Compromisso e confiança estabelecem um vínculo entre dois seres e sublinha o caráter mútuo desta relação que procura estabelecer uma aliança ampla que os envolva entre si e os aproxime de Deus. Este princípio leva à obediência a Deus e ao outro, permitindo a penetração de uma regulamentação dentro dos lares, nos leitos conjugais (PIMENTEL,2005, p. 25). 
Nada obstante, essas características, onde esferas públicas e privadas se confundem, fé e obediência se misturam para a manutenção econômica, sentimentos de amor aos filhos e aos cônjuges, como da educação afetiva não são características desse tempo, onde o importante é a preservação do status e não de uma constituição familiar como se pensa hoje em dia.

Contudo essa evolução não é um processo simples, mas passa pelas relações com os filhos onde em relações internas de âmbito econômico, a criança era "um acessório supérfluo" Costa (1989), já que para o senhor das terras, o que realmente importava era que seu filho se tornasse adulto o mais rápido possível, para que herdasse os bens e trabalhasse a fim de enriquecer ainda mais a família. $\mathrm{O}$ autor ainda destaca que, a vida das crianças se resumia a economia doméstica, contribuindo no que fosse necessário para o meio de subsistência familiar, somente na adolescência adquira um pouco mais de atenção da família, já que neste momento era adultilizado de forma precoce, assumindo funções mais importantes no seio familiar. Fato, que por muitas vezes deixaram crianças abandonas ao cuidado alheio, como da invenção da Casa da Roda, onde,

\begin{abstract}
Um dos objetivos [...] para a criação da Casa da Roda foi humanizar o abandono, evitando que parte dessas crianças perecesse de fome ou frio ou fossem devoradas por animais [...] Contudo, essa instituição não teve como objetivo salvar vidas "inocentes", haja vista o alto índice de mortalidade que girava em torno de $70 \%$ das crianças expostas, mas depurara experiência da morte, enclausurá-la, retirá-la do espaço público e construir outras sensibilidades coletivas e individuais na esteirado investimento civilizatório (NASCIMENTO, 2007, p. 74).
\end{abstract}

Assim, a Roda dos Expostos tornou-se um depósito de crianças, que em pouco tempo favoreceu ao grande número de mortalidade infantil, devido às condições precárias do estabelecimento para o atendimento da demanda.

Nesse viés de apontamentos histórico familiar, é importante também discorrer sobre o papel da mulher ao longo do processo da formação da família, assim como, foi tratado do papel patriarcal e dos filhos na família brasileira. No Brasil entre os séculos XVII e XIX, a mulher exerce um papel coadjuvante em diversas esferas sociais, ficando quase sempre sobre a tutela do pai, do irmão mais velho ou do marido. Assim, por um lado, o casamento tornava-se uma oportunidade única de fugir do julgo familiar, pois o casamento era uma das poucas oportunidades de escapar do poder e violência do pai, da subalternidade e da dependência financeira. Por outro lado, para as jovens órfãs, o casamento significava segurança e a possibilidade de iniciar uma nova vida junto de outra pessoa, deixando de lado as vivências e experiências em conventos, orfanatos ou com seus tutores legais. "Em caso de morte dos pais, entre as responsabilidades impostas aos tutores, estava a de arranjar marido para as filhas mulheres" (VIANNA; BARROS, 2005, p. 168). Pois, caso não encontrassem pretendentes, as 
mulheres ficavam trancadas em conventos, os pais preferiram dessa forma, a entregar suas filhas a homens de outra categoria social, que não oferecesse alguma vantagem de interesse dos tutores.

De tal modo, nessa breve análise, pode-se perceber que, a família patriarcal colonial faz sua transição para a família burguesa, levando consigo muitos atributos culturais que, com a industrialização e a necessidade de ganho de salários para manutenção dessas famílias, vão alterando de forma contínua o formato familiar e o papel de cada um dos seus membros. A família burguesa era um mundo isolado, uma ilha, longe de ser inclusiva, pelo contrário, pelas análises feitas até aqui, percebe-se totalmente o contrário, trata-se de um modelo de família que se fechava em si mesma e por esse motivo exclui toda e qualquer interferência externa.

\section{A Família e as Novas Composições Familiares de acordo com a Legislação Brasileira}

A partir do entendimento da família patriarcal e sua imposição na sociedade, o direito brasileiro foi construído visando à proteção desse arranjo familiar, desconsiderando todos os demais existentes ao longo da história, postura essa que se consolidou por meio de legislações relacionadas aos direitos políticos, civis e sociais. É somente com o movimento de redemocratização do país e com a promulgação da Constituição Federal de 1988, que se tentou romper com lógica do modelo de família tradicional nuclear, abrindo-se espaço para outras composições familiares na proteção estatal (BRASIL, 1988).

Destarte, para o aprofundamento desse trabalho, é necessário analisar como a instituição familiar é entendida em três importantes documentos vigentes no Brasil: a) A família de acordo com a Declaração Universal dos Direitos Humanos (DUDH); b) A família de acordo com as Constituições brasileiras e; A família de acordo com o Código Civil brasileiro.

A Declaração Universal dos Direitos Humanos (DUDH) foi instituída pela Resolução ONU nº 217-A de 10 de dezembro de 1948 na Assembleia Geral das Nações Unidas em Paris (UNESCO, 1998). Sendo o Brasil um dos pactuantes signatários, acolheu os princípios e diretrizes desse documento, incluindo no que tange a família. Assim sendo, a seguir analisarse-á o Art. 16 da DUDH.

“1. A partir da idade núbil, o homem e a mulher têm o direito de casar e de constituir família, sem restrição alguma de raça, nacionalidade ou religião. Durante o casamento e na altura da sua dissolução, ambos têm direitos iguais" (UNESCO, 1998, p. 4): Nesse parágrafo a DUDH entende o direito das pessoas em contrair matrimônio indiferente da sua raça, nacionalidade ou religião, mas não faz menção a gênero. Em outras palavras, a DUDH não faz 
referência ao direito de pessoas do mesmo sexo formar família por meio do casamento, configurando um modelo de família homoafetiva, ainda que não especifique a possibilidade somente do modelo tradicional.

"2. O casamento não pode ser celebrado sem o livre e pleno consentimento dos futuros esposos" (UNESCO, 1998, p. 4): Nesse parágrafo a DHDU procura coibir a formação familiar por meio de casamentos arranjados, nos quais prevaleciam os acordos financeiros em relação da vontade dos cônjuges.

“3. A família é o elemento natural e fundamental da sociedade e tem direito à proteção desta e do Estado" (UNESCO, 1998, p. 4): Esse parágrafo deixa clara a relevância da instituição familiar dentro da sociedade. A família, junto com a Igreja e o Estado sempre desempenharam papeis fundamentais dento das organizações sociais, sendo a família considerada a mais importante para o desenvolvimento dos indivíduos.

Em outras palavras, a DUDH não faz referência ao direito de pessoas do mesmo sexo formar família por meio do casamento, configurando um modelo de família homoafetiva, mas também não faz referências a possibilidade exclusiva modelo tradicional.

Percebe-se, pois, uma preocupação, como apontado pela UNESCO (1988) em abarcar a família como a mais importante organização social, aberta as disposições de debate e legalidade frente às novas composições que se configuram como matrimônio e mesmo paternidade.

Diante a emancipação histórica das conquistas culturais de caráter internacionais que devem ser apreciados legalmente, como do entendimento da família patriarcal e sua imposição na sociedade, o direito brasileiro foi se construindo visando a proteção desse novo arranjo familiar, desconsiderando alguns pontos, aperfeiçoando e criando outros daqueles existentes ao longo da história que já se tornaram obsoletos e inaplicáveis, solidificando por meio de legislações, direitos políticos, civis e sociais. É somente com o movimento de redemocratização do país e com a promulgação da Constituição Federal de 1988, que se tentou romper com a lógica do modelo de família tradicional nuclear, abrindo-se espaço para outras composições familiares na proteção estatal (BRASIL, 1988).

A primeira alteração significativa é percebida no texto em que se introduz o tema família. Na CF de 1967 o Art. 167 deixa claro que a família é constituída pelo casamento e, portanto, tem direito a proteção do poder público. Já na CF e 1988 o Art. 226 traz a instituição familiar como sendo a base da sociedade e, desse modo tem especial proteção do Estado. $\mathrm{O}$ último documento preserva a entidade familiar o papel de destaque que sempre ocupou na 
sociedade, contudo, deixa aberta a possibilidade de diferentes entendimentos do termo família, não resumindo somente ao ato de contrair o matrimônio.

É importante pontuar que, até o ano de 2011, a celebração do casamento civil somente poderia ocorrer entre um homem e uma mulher, configurando, portanto, o modelo de família tradicional. O Legislador que se omite a discutir a proteção legal do arranjo familiar composto por pessoas do mesmo sexo puramente por preconceitos. Isso está sendo vencida por outras áreas que reconhecem o direito a igualdade dessa nova configuração familiar. Mesmo sem a tutela legal do legislativo, houve a aprovação durante a $169^{\mathrm{a}}$ Sessão Plenária do Conselho Nacional de Justiça (CNJ), por meio da Resolução n.175, de 14 de maio de 2013, publicada em 15/05/2013, no Diário da Justiça Eletrônico (DJ - e), vigente a partir de 16/05/2013, a realização do casamento civil homoafetivo (STF, 2011).

Portanto, a partir de 16 de maio de 2013, começaram a ser celebrados casamentos civis entre pessoas do mesmo sexo no Brasil, e assim, pelo Poder Judiciário, houve o reconhecimento desse arranjo familiar e, por conseguinte, todos os direitos inerentes às famílias inclusive de adoção. Portanto, a família não importando qual a sua composição (arranjo), é considerada pelo legislador como melhor ambiente para o desenvolvimento da criança, desde que nesta entidade familiar existam relações consideradas saudáveis, desta forma, estabelece o Art. 19 do Estatuto da Criança e do Adolescente (BRASIL, 1990, p. 5). Deste modo, é necessária essa abertura a essas novas composições familiares em sua legalidade para a efetiva prática atribuída as leis conquistadas. Assim, como cita Xavier (2015):

\footnotetext{
A nossa Constituição Federal [...] por uma opção política que tem por base o respeito à liberdade do indivíduo, decidiu que, embora se reconheça a família fundada na união estável, sendo essa merecedora de total proteção do Estado, enquanto entidade familiar, ainda há uma nítida preferência pelo casamento, instituto que garante segurança jurídica aos seus integrantes, devendo, portanto, a legislação ordinária facilitar àqueles que vivem informalmente a obtenção de um status jurídico mais seguro (XAVIER, 2015, p. 119-120).
}

Por conseguinte, observa-se que, nenhum arranjo familiar é diferente em sua convivência, no caso dos casais homoafetivos é apenas uma questão de foro íntimo, que é a sua orientação sexual. No Código Civil, assim como aconteceu na constituição, o casamento deixou de configurar o modelo patriarcal, seguindo as mudanças ocorridas nas sociedades modernas (FARO, 2011). De acordo com a autora, o Código Civil trata do casamento de modo democrático por estabelecer a igualdade dos direitos e deveres entre os cônjuges (Art. 1.511. 1.565) e a gratuidade da sua celebração (Art. 1.512) (BRASIL, 2002).

No entanto, mesmo que, cada vez seja mais comum este arranjo familiar não é reconhecido pelo legislador, o que demonstra de forma clara o preconceito, ainda não superado 
pela sociedade brasileira sobre determinadas composições familiares. Assim, todas as demais composições familiares têm cada um à sua peculiaridade, que deverá ser observada pelo legislador para garantia da proteção nos dispositivos legais.

\section{A Família e as Novas Composições de Familiares de acordo com as Políticas Públicas de Assistência Social}

Segundo Schmidt (2008), para que ocorram as mudanças necessárias nas políticas públicas, é necessário que se respeite todas as fases exigidas pela burocracia institucional do Estado, que perpassa pelo “ciclo político" (SCHMIDT, 2008, p. 2315), que envolve as seguintes etapas: definição de problemas de: Inserção na agenda política; Formulação; Implementação. Para o autor, a avaliação das políticas públicas, cada etapa iniciando com a inserção na agenda política de um problema social, nesta primeira etapa, existe a necessidade de percepção e definição dos problemas.

Ao reconhecer e definir o problema, tanto o Estado, quanto à sociedade civil, identifica algumas fragilidades nela mesma (como a própria vulnerabilidade social) e buscam políticas públicas capazes de operacionalizar a solução de tais disfunções. Após essa etapa, passa-se à Inserção na agenda política, momento em que se busca fomentar a discussão entre o Estado e Sociedade, com o intuito de obter maior resolutividade para a demanda apresentada.

Assim, podemos inferir que as políticas públicas no Brasil, buscam respeitar e seguir na maioria das vezes todas as etapas do ciclo político, promovendo a aproximação do aparelho do Estado, das novas demandas sociais que emergem conforme as relações vão se complexificando. É no escopo deste amplo debate, que se estruturou a política pública de assistência social, visando proteger as famílias e indivíduos em vulnerabilidade e risco social no Brasil, a partir da Constituição Federal de 1988.

Partindo dessa premissa legal, como foi visto, a família é "o núcleo natural e fundamental da sociedade [com] direito à proteção da sociedade e do Estado.” (ONU, 2009, p. 10). Mas como assegurar esse direito à família e prestar-lhe assistência dentro de uma compreensão ainda complexa em sua compreensão?

No Brasil, a política pública de Assistência Social se realiza de forma integrada às políticas setoriais (Educação, saúde, cultura, esporte, entre outros), considerando as desigualdades socioterritoriais. Igualmente,

A intersetorialidade deve expressar a articulação entre as políticas públicas, por meio de ações conjuntas destinadas à proteção social básica e especial e ao enfrentamento das desigualdades sociais identificadas nas distintas áreas (COUTO et al., 2010, p.39). 
De modo semelhante, para Mendes; Aguinski (2009), as estratégias de fortalecimento da Política de Assistência Social, devem pautar-se na valorização de todos os sujeitos envolvidos - usuários, trabalhadores, gestores, conselheiros - com estímulo à corresponsabilidade e ao protagonismo destes sujeitos.

Concomitante a estes objetivos esperados, a concepção de família para a Assistência Social deve ser embasada na pluralidade concebida na Constituição Federal que vai ao encontro da realidade das camadas que mais carecem da assistência (PICARELLI, 2007). Para o autor, ao se restringir o conceito de família não se apresentará "a realidade familiar, não permitindo, assim, uma real aferição da situação de necessidade para que se concretize o amparo assistencial a quem efetivamente dele necessite." (PICARELLI, 2007, p. 14).

Ainda que as políticas públicas de Assistência Social no Brasil procurem privilegiar as mais variadas formas de composições familiares, "observa-se que nos CRAS por vezes existem práticas que contribuem para o controle do viver e para a produção de modos de vida hegemônicos.” (SANTOS; HECKERT; CARVALHO, 2017, p. 8). Tais políticas, ao mesmo passo que atendem a integralidade familiar encontra subsídios para transferir a responsabilidade da proteção e da promoção social do Estado para a família, sobrecarregando, quase sempre, a mulher. Como esse encargo é complexo, "os efeitos dessas práticas são a estigmatização das camadas sociais mais empobrecidas como desajustadas, contribuindo para a culpabilização dessa população pelas dificuldades que enfrentam. " (SANTOS; HECKERT; CARVALHO, 2017, p. 8).

Além disso, tanto a PNAS 2004 quanto a NOB/SUAS/2005 "não conseguiram garantir o cumprimento da universalização dos direitos sociais" (SOARES, 2012, p. 8). Isso porque o "o conceito de família na assistência social pressupõe a filiação, a existência da parentalidade com filhos" (SOARES, 2012, p. 8).

Todavia, ainda é preciso repensar o problema da aplicação das políticas públicas, quando os sistemas ainda se organizam de modo a impermeabilizar a responsabilidade da assistência social diretamente proporcional às conquistas e composições que se constituem na família contemporânea, como, por exemplo, no caso da Bolsa família, que ainda recai sobre a figura da mulher e da filiação que se dispõe sobre a figura feminina. 


\section{Considerações Finais}

Após a pesquisa bibliográfica e documental sobre proteção social e as novas composições familiares é importante destacar que as contribuições trazidas pela Constituição de 1988 são na maioria relacionadas aos direitos sociais (LINS, 2013). Pois assegurou na legislação a Assistência Social, Saúde e Previdência Social como direito e deste modo, foi obrigatória à dedicação desta legislação a família também. Assim, pode-se perceber como as mulheres eram vistas e desvalorizadas perante a legislação que sob um viés de controle, não permitia que exercessem os mesmos direitos dos homens na sociedade. As mulheres eram consideras relativamente incapazes juridicamente e dependiam dos maridos para todas as atividades civis, não podendo assinar contratos, comprar, vender, enfim, quase nenhum ato da vida civil poderia ser executado sem a permissão de um homem.

A Constituição Federal de 1988 é promulgada trazendo em seu bojo essa quebra de paradigma, para igualar todos perante a Lei, afastando uma ideologia machista e preconceituosa implícita nas legislações anteriores, proporcionando a igualdade entre o homem e a mulher. A Constituição 1988 apresentou mudanças significativas, já que antes dela, caso o homem não conseguisse se manter no mercado de trabalho era visto pela sociedade geralmente como vadio, preguiçoso entre outras rotulagens que lhes eram impostas (LINS, 2013).

Já a mulher, ao contrário, não podia acessar o mercado, sem várias críticas conservadoras, ou seja, havia restrições para a mulher casada, do lar, que queriam trabalhar fora do espaço doméstico, tudo isso pela concepção histórica da divisão sexual do trabalho. Essa divisão, que estabelecia papéis bem definidos já vistos anteriormente para cada membro na família, pois ao homem cabiam todas as articulações necessárias no meio econômico e na sociedade (externa) e para as mulheres as tarefas domésticas (interno) e de forma geral, em nenhum momento poderia ultrapassar esse limite. Portanto, no que toca ao papel da mulher na sociedade, tanto na Constituição Federal (1988) quanto no Código Civil (2002) a mulher adquiriu direitos colocando-a em igual posição como o homem (MALUFF, 2010).

No que se refere aos novos modelos de famílias, a Constituição de 1988 "inovou" ao considerar outros tipos de composições familiares diferentes do modelo tradicional patriarcal (conjugal ou matrimonial), como a união estável e a monoparentalidade (MALUFF, 2010). Essas alterações foram possíveis porque o "intervencionismo estatal foi barrado pela disposição prevista no artigo 1.513 do Código Civil de 2002, com a finalidade de tornar claro e efetivo o princípio do livre planejamento familiar, na forma do artigo 226, $\S 7^{\circ}$, da CRFB/1988." (HOGEMANN; SANTOS, 2016, p. 37). Desse modo, a nova legislação acompanhando as 
mudanças ocorridas na sociedade, proporciona a igualdade de direitos entre homens e mulheres e o reconhecimento de novas composições familiares, possibilitando as mudanças sociais e culturais, em especial de valores patriarcais, mesmo que de forma lenta e gradual, como foco na proteção da família pelo Estado.

Essa evolução jurídica no sentido de acompanhar a realidade popular é importante visto que é "impossível imaginar, na sociedade contemporânea, um padrão de arranjo familiar que sirva como delimitação do conceito de família já que as balizas normativas dogmáticas e cerceantes foram finalmente rompidas pelo afeto." (HOGEMANN; SANTOS, 2016, p. 37). Contribuindo com Hogemann; Santos (2016), Faro (2011, p. 5) reitera que o "único requisito para constituição da família é o laço de afetividade entre seus membros, não importando quaisquer outras circunstâncias [...].” (FARO, 2011, p. 5).

Em que pese o desdobramento, o princípio da igualdade se desdobra em igualdade e minorias, este último entendido "um grupo de cidadão de um Estado, em minoria numérica ou em posição não dominante neste Estado, dotado de características étnicas, religiosas ou linguísticas diferentes da maioria da população [...]” (CANOTILHO, 2003, p. 387), como por exemplo, o idoso que vive dentro de uma comunidade de maioria com faixa etária inferior.

Por outro lado, também são garantidos os preceitos de igualdade e grupos vulneráveis, que seria outro desdobramento que não se confunde com minorias, já que vulneráveis são consideradas todas aquelas pessoas que facilmente podem ser feridas física ou moralmente, e por isso, necessitam de uma proteção diferenciada do Estado, considerando que possuem condições políticas, sociais e culturais distintas. Em que pese à questão dos indivíduos classificados socialmente como "minorias", Gohn (2005), esclarece que em muitos casos essas minorias são a maioria, como mulheres, negros e etc., que buscam o reconhecimento dos seus direitos. Este movimento surge em paralelo com outras reivindicações, como os direitos sociais, políticos, econômicos, humanos e culturais na última década do século XX.

Para a autora, o direito das minorias seria o "direito à diferença", ou seja, a garantia de proteção do Estado, mesmo que esses não se enquadrem nos modelos padronizados pela sociedade, pois, o não reconhecimento tornará os indivíduos vulneráveis e fragilizados perante a sociedade. No tocante a vulnerabilidade, é necessário o entendimento que não está vinculada apenas hipossuficiência, já que as questões econômicas seriam apenas um critério da vulnerabilidade, a autora defende a ideia de que, existem diferentes dimensões de vulnerabilidade a qual as famílias podem estar inseridas.

Portanto, conclui-se que, para exercer o seu papel, o Estado necessita estruturar políticas públicas que deverão dar condições de autonomia para superação das vulnerabilidades dos 
indivíduos, independente do formato familiar. A política pública deve considerar todas as mudanças ocorridas na sociedade, em especial nas composições familiares existentes e muitos outros que possam surgir, pois, como puderam ser observadas, as famílias estão em constantes mudanças. Elaborada para atender essas demandas a Política Pública de Assistência Social, com seus serviços, programas, projetos e benefícios socioassistenciais estipulados na Lei Orgânica de Assistência Social (LOAS), deve estar voltada para a pluralidade familiar que é a mais próxima do papel do Estado na proteção social.

\section{Referências}

ARANTES, Fernanda Inêz Siqueira. A mulher desdobrável: a articulação entre as esferas pública e privada. Belo Horizonte, 2011. 153f.

ARAÚJO, Walter da Rocha. Representações sociais sobre família e classes sociais. Dissertação (Mestrado). Centro de Ciências Aplicadas, Universidade Federal de Pernambuco, Maceió, 116f. 2003.

ARIÈS, Philippe. História Social da Criança e da Família. LCT, Rio de Janeiro, 2011.

BARRETO, Ana Cristina Teixeira. A Igualdade entre homens e mulheres no ordenamento jurídico brasileiro. Disponível em: <https://www.anadep.org.br/wtksite /cms/conteudo/9875/IGUALDADE_20ENTRE_20HOMENS_20E_20MULHERES_20NO_2 0ORDENAMENTO_20_20_20_20_20_20JUR_DICO_20BRASILEIRO_1_.pdf >. Acesso em 12/abr 2014.

BATTINI, Odária. Política e Planejamento Social: decifrando a dimensão técnicooperativa na prática profissional. (2007). Disponível em: <http://unesav.com. br/ckfinder/userfiles/files/planejamento-social.pdf>. Acesso em: $30 \mathrm{dez} 2018$.

BEHRING, E. R.; BOSCHETTI, I. Política social: fundamentos e história. 9. ed. São Paulo: Cortez, 2011

BERQUÓ, Elza. Arranjos Familiares no Brasil: Uma Visão Demográfica. In L. M. Schwarcs (org.), História da Vida Privada no Brasil (vol. 4). São Paulo, Companhia das Letras, pp. 411437, 1998

BRASIL. Constituição da República Federativa do Brasil de 1988, de 5 outubro de 1988. Disponível em: <http://www.planalto.gov.br/ccivil_03/Constituicao/Constituicao.htm>. Acesso em: 26 nov 2018.

BRASIL. Constituição dos Estados Unidos do Brasil de 1946, de 18 de setembro de 1946. Disponível em: <http://www.planalto.gov.br/ccivil_03/Constituicao/Constituicao46.htm>. Acesso em: 26 nov 2018. 
BRASIL. Constituição dos Estados Unidos do Brasil, de 10 de novembro de 1937. Disponível em: <http://www.planalto.gov.br/ccivil_03/Constituicao/Constituicao37.htm>. Acesso em: 26 nov 2018.

BRASIL. Constituição Imperial de 1924. Constituição Política do Império do Brasil, elaborada por um Conselho de Estado e outorgada pelo Imperador D. Pedro I, em 25.03.1824. Disponível em: <http://www.planalto.gov.br/ccivil_03/Constituicao/Constituicao24.htm>. Acesso em: 26 nov 2018.

BRASIL. Lei n $^{\text {8 }}$ 8.069, de 13 de julho de 1990. Dispõe sobre o Estatuto da Criança e do Adolescente e dá outras providências. Disponível em: <http://www.planalto.gov.br/ccivil_03/LEIS/L8069Compilado.htm>. Acesso em: 29 dez 2018.

BRASIL. Política Nacional de Assistência Social PNAS/ 2004 e Norma Operacional Básica NOB/SUAS. Ministério do Desenvolvimento Social e Combate à Fome Secretaria Nacional de Assistência Social. Brasília, Novembro de 2005. Disponível em: <https://www.mds.gov.br/webarquivos/publicacao/assistencia_social/Normativas/PNAS2004. pdf>. Acesso em: $29 \mathrm{dez} 2018$.

BRASIL. Presidência da República. Decreto-Lei no 4.657, de 4 de setembro de 1942. Lei de Introdução ao Código Civil Brasileiro. Disponível em: <http://www.planalto.gov.br/ccivil_03/Decreto-Lei/Del4657.htm>. Acesso em: 19 nov 2018.

BRASIL. Presidência da República. Lei no 10.406, de 10 de janeiro de 2002. Institui o Código Civil. Disponível em: <http://www.planalto.gov.br/ccivil_03/LEIS/2002/L10406.htm\#art2044>. Acesso em: Acesso em: 03 dez 2018.

BRASIL-CDC. Decreto $\mathbf{n}^{0}$ 99.710, de 21 de novembro de 1990. Promulga a Convenção sobre os Direitos da Criança. Disponível em: <http://www.planalto.gov.br/ccivil_03/Decreto/1990-1994/D99710.htm>. Acesso em: 28 nov 2018.

CANEVACCI, Massimo. Dialética da família. Ed Brasiliense, $4^{\text {a }}$ ed., Rio de Janeiro, 1985.

CANOTILHO, José Joaquim Gomes. Direito Constitucional e Teoria da Constituição. 7 ed. Coimbra: Edições Almedina. 2003.

CASTELlO BRANCO, Helena Alvim. Família: Indicadores Sociais 1981/1987. Rio de Janeiro, RJ: IBGE, 1989. V. 1, 28p.

CONSELHO NACIONAL DE ASSISTÊNCIA SOCIAL (CNAS). Resolução No 207, de 16 de dezembro de 1998. Aprova por unanimidade a Política Nacional de Assistência Social PNAS e a Norma Operacional Básica da Assistência Social - NOB2. Disponível em: <http://www.mds.gov.br/webarquivos/legislacao/assistencia_social/resolucoes/1998/Resoluca o\%20CNAS\%20no\%20207-\%20de\%2016\%20de\%20dezembro\%20de\%201998.pdf >. Acesso em: 15 nov 2018.

CORRÊA, Mariza. Repensando a família patriarcal brasileira. Cad. Pesq., São Paulo, (37): 516, Mai, 1981. 
COSTA, Jurandir Freire. Psicanálise e contexto cultural. Ed. Campus, São Paulo, 1989.

COUTO, B. R. et al. O Sistema Único de Assistência Social no Brasil: uma realidade em movimento. $3^{\text {a }}$. ed. São Paulo: Cortez, 2012.

COUTO, B. R. O direito social e a assistência social na sociedade brasileira: uma equação possível? 4a . ed. São Paulo: Cortez, 2010.

D’INCAO, Maria Ângela (org.). Amor e família no Brasil. São Paulo: Contexto, 1989.

DECLARAÇÃO UNIVERSAL DOS DIREITOS HUMANOS (DUDH). Adotada e proclamada pela resolução 217 A (III) da Assembleia Geral das Nações Unidas em 10 de dezembro de 1948. BR/1998/PI/H/4 VER. Disponível em: <http://unesdoc.unesco.org/images/0013/001394/139423por.pdf>. Acesso em: 15 out 2018.

FARO. Luciana Martins de. A Família no novo Código Civil. Revista da Escola Superior da Magistratura de Sergipe, $n^{\circ}$ 03. 2002.

FISCHLOWITZ, E. Proteção social à família. Rio de Janeiro: FGV, 1963.

FONSECA, João José Saraiva da. Metodologia da pesquisa científica. (Apostila) Fortaleza: UEC, 2002.

GIL, Antônio Carlos. Como elaborar projetos de pesquisa/Antônio Carlos Gil. - 4. ed. - São Paulo: Atlas, 2002.

GIORGIS, José Carlos Teixeira. Direito de Família Contemporâneo. Ed. Livraria do Advogado. Porto Alegre, 2010.

GOHN, Maria da Glória. O protagonismo da sociedade civil: movimentos sociais, ONGs e redes solidárias. São Paulo: Cortez, 2005.

GONÇALVES, Elisa Pereira. Iniciação à pesquisa científica. São Paulo: Alínea, 2003.

HOGEMANN, Edna Raquel Rodrigues Santos.; SANTOS, Marcelo Pereira dos. Família, Casamento e Descompassos Normativos do Código Civil Brasileiro no Século XXI. Revista Brasileira de Direito Civil em Perspectiva. Curitiba, v. 2, n. 2, p. 21-41. Jul/Dez. 2016.

MADALENO, Rolf. Curso de direito de família. Ed. Forense, $5^{\text {a }}$ ed. Revista, atualizada e ampliada, 2013.

MALUF, Adriana Caldas do Rego Freitas Dabus. Novas modalidades de família na pósmodernidade. Tese (Doutorado) - Faculdade de Direito da Universidade de São Paulo (USP) - SP, 2010.

MEDEIROS, A. P.; NELSON, R. A. R. R. A redefinição do conceito de família na perspectiva do neoconstitucionalismo. Revista de Direito Privado. São Paulo. V.55, p. 262, 2013.

MENDES, Jussara Maria Rosa. AGUINSKY, Beatriz Gersherson. Apresentação. Revista Textos \& Contextos Porto Alegre v. 8 n.1 p. 1-2. jan./jun. 2009. 
MIOTO, R. C. T. Considerando sobre o trabalho social com famílias: proposta para discussão. Seminário Nacional de Trabalho Social com Famílias na Política Nacional de Assistência Social - Promovido pela Secretaria Nacional de Assistência Social/MDS. Brasília: SNAS/MDS. 2014. p. 1-18.

NASCIMENTO, Alcileide Cabral do. Vida e esperança: o trabalho feminino na criação de bebês no Recife (1789 - 1831). Revista Esboços, Volume 14, nº 17 — UFSC, 2007.

ORGANIZAÇÃO DAS NAÇÕES UNIDAS (ONU). Declaração Universal dos Direitos Humanos. Resolução 217-A III da ONU, de 10 de dezembro 1948. Disponível em: $<$ https://www.ohchr.org/EN/UDHR/Pages/Language.aspx?LangID=por $>$. Acesso em: $10 \mathrm{dez}$ 2018.

PIMENTEL, Helen Ulhôa. O casamento no Brasil Colonial: um ensaio historiográfico. Em Tempo de Histórias - Publicação do Programa de Pós-Graduação em História PPG-HIS/UnB, n.9, Brasília, 2005.

RODRIGUES, M. M. A. Políticas públicas. São Paulo: Publifolha, 2010.

SANTOS, Keli Lopes.; HECKERT, Ana Lucia Coelho.; CARVALHO, Silvia Vasconcelos Carvalho. Família e mulher como instrumentos de governo na assistencia social. Psicologia \& Sociedade, 29: e158080, 2017.

SCHIMIDT, João Pedro. Para entender políticas públicas: aspectos conceituais metodólogicos. REIS, Jorge Renato; LEAL, Rogério Gesta (Orgs.). Direitos sociais \& políticas públicas: desafios contemporâneos.Santa Cruz do Sul:Edunisc, p. 2307-2333, 2008.

SCOTT, Ana Silvia. Família: O caleidoscópio dos arranjos familiares. In: PINSKY, Carla Bassanezi; PEDRO, Joana Maria (org.). Nova história das mulheres no Brasil. São Paulo: Contexto, 2013.

SEGALEN, Martine. Sociologia da família. Lisboa, Portugal: Terramar, 1996.

SHORTER, Edward. The Making of the Modern Family. New York: Basic Books, 222p. 1975.

SIQUEIRA, Alessandro Marques de. O conceito de família ao longo da história e a obrigação alimentar. Âmbito Jurídico, Rio Grande do Sul, 2018.

SLENES, Robert Wayne Andrew. Na senzala, uma flor - Esperanças e recordações na formação da família escrava: Brasil Sudeste, século XIX. Editora da Unicamp (2a edição), 2011.

SOARES, Ricardo Pereira. A concepção de família da política de assistência social - Desafios à atenção a famílias homoparetais. Dissertação (Mestrado). Programa de Pós-Graduação em Política Social (PPGPS), Universidade de Brasília (UnB). Brasília, 2012.

SOUZA, Marcela Coelho de. Parentes de sangue: incesto, substância e relação no pensamento Timbira. MANA 10(1):25-60, 2004. 
TERUYA, Marisa Tayra. 2000. A família na historiografia brasileira: bases e perspectivas teóricas. In: XII Encontro Nacional de Estudos Populacionais (ABEP), 2000, Caxambú/MG. Brasil, 500 anos: Mudanças e Continuidades.

TRIGO, Maria Helena Bueno. Amor e casamento no século XX. In: D'INCAO, Maria Ângela et al. (org.). Amor e família no Brasil. São Paulo: Contexto, 1989.

VANZETTO, Antonia Alves. O Sistema Único De Assistência Social e a centralidade na família. In: $2^{\circ}$ Seminário Nacional de Assistência Social Estado e Políticas Sociais no Brasil. UNOESTE - Campus de Cascavel, de 13 a 15 de outubro, 2005.

VENOSA, Sílvio de Salvo. Direito Civil: direito das sucessões. 14ª ed. São Paulo: Atlas, 2014.

VENOSA, Sílvio de Salvo. Direito Civil: direito de família $9^{a}$ ed. Vol 6, São Paulo: Atlas, 2009.

VIANNA, Paula Cambraia de Mendonça; BARROS, Sônia. O papel das políticas sociais frente à reestruturação do modelo assistencial em saúde mental. Saúde em debate: Rio de Janeiro: 29(69): 27-35, jan-abr/2005.

WAMBIER, Teresa Arruda Alvim. Nulidades do Processo e da Sentença. Revista dos Tribunais, 3 ed. São Paulo: 1993.

XAVIER, Fernanda Dias. União estável e casamento: a impossibilidade de equiparação à luz dos princípios da igualdade e da liberdade [recurso eletrônico] / Fernanda Dias Xavier. - Dados eletrônicos. - Brasília: TJDFT, 2015.

ZONABEND, Françoise. An anthropoligical perspective on kinship and the family. In: BURGUIÈRE, André, et al. A history of the family. Cambridge: Harvard University Press, 1996.

\section{Como citar este artigo (Formato ABNT):}

CÓRDOVA, Zolnei Vargas Ernesta de; CÓRDOVA, Ismael de; OLIVEIRA, Katiuscia Angélica Micaela de. A Família como Centralidade nas Políticas Públicas e as Novas Composições Familiares: A adequação jurídica, política e temporal sobre a família contemporânea. Id on Line Rev.Mult. Psic., Maio/2020, vol.14, n.50, p. 991-1007. ISSN: 1981-1179.

Recebido: $12 / 05 / 2020$

Aceito: $15 / 05 / 2020$ 